\title{
Frailty Status Predicts New Long-term Care Insurance Certification in Hepatitis C Patients Receiving Antiviral Therapy
}

\author{
KENICHI NAKAMURA ${ }^{1}$, KAZUNORI KUSUMOTO ${ }^{1,2}$, YOSHINORI OZONO $^{1}$, KAZUO KUROKI ${ }^{3}$, \\ YUNOSUKE MATSUURA ${ }^{2}$, TOSHIHIRO MUKUDA ${ }^{2}$, TOSHIMASA OCHIAI ${ }^{2}$, MAI TSUCHIMOCHI ${ }^{1}$, \\ HISAYOSHI IWAKIRI ${ }^{1}$, SATORU HASUIKE ${ }^{1}$, KAZUYA SHIMODA ${ }^{1}$ and KENJI NAGATA ${ }^{1}$ \\ ${ }^{1}$ Department of Gastroenterology and Hematology, Faculty of Medicine, \\ University of Miyazaki, Miyazaki, Japan; \\ ${ }^{2}$ Koga General Hospital, Miyazaki, Japan; \\ ${ }^{3}$ Kushima Municipal Hospital, Miyazaki, Japan
}

\begin{abstract}
Background/Aim: Direct-acting antiviral (DAA) therapies for patients with hepatitis $C$ virus (HCV) infection deliver higher cure rates and lower frequencies of adverse events than existing therapies, though DAA treatment costs $\$ 45,000-64,000$ in Japan. The prognosis of patients who require new long-term care insurance (LTCI) certification is inferior to that of patients who do not. Here, we clarify the factors associated with new LTCI certification in elderly patients with HCV infection who undergo DAA therapy. Patients and Methods: We retrospectively surveyed 53 patients aged $\geq 70$ years who were treated with DAAs, and evaluated the factors associated with new LTCI certification. Results: Of 53 patients, 10 required new LTCI certification. Age $\geq 85$ years and a modified Japanese Cardiovascular Health Study index $\geq 2$ were independently associated with new LTCI certification. Conclusion: In elderly HCV patients, poor frailty status strongly predicted new LTCI certification after DAA therapy.
\end{abstract}

Hepatitis $\mathrm{C}$ virus (HCV) infection is one of the major causes of liver-related diseases such as chronic hepatitis $(\mathrm{CH})$, liver cirrhosis (LC), and hepatocellular carcinoma (HCC) (1-3). Achieving a sustained virological response (SVR) by directacting antiviral agent (DAA) therapy reduces the incidence of

This article is freely accessible online.

Correspondence to: Dr. Kenji Nagata, Department of Gastroenterology and Hematology, Faculty of Medicine, University of Miyazaki, 5200 Kihara, Kiyotake, Miyazaki 889-1601, Japan. Tel: +81 985859121 , Fax: +81 985855194, e-mail: nagatakj@med.miyazaki-u.ac.jp

Key Words: Frailty, long-term care insurance certification, Japanese Cardiovascular Health Study index, Kihon Checklist, hepatitis C virus.
HCC in patients with HCV infection (4, 5). In Japan, the prevalence of anti-HCV antibodies in the general population was estimated to be $0.9 \%$, and significantly increased with age (6). In fact, most Japanese patients with hepatitis $\mathrm{C}$ are elderly, and those aged $\geq 70$ years account for more than $50 \%$ of HCV carriers (7). While new DAA therapies for patients with $\mathrm{HCV}$ infection deliver higher cure rates and lower frequencies of adverse events than existing therapies (8), the cost of these drugs is approximately 5-7 million yen $(\$ 45,000-64,000)$ in Japan (9). All patients with $\mathrm{HCV}$ infection are considered candidates for DAAs, except for those with shorter life expectancies. In Japan, the additional life expectancy at the age of 70 is 15.7 years in men and 19.8 years in women (10). To appropriately allocate limited healthcare resources, decision-making about administering DAAs to the elderly patients should take into consideration these individuals' additional life expectancy, as well as traditional contraindications based on adverse effects $(11,12)$. Frailty is defined as a clinical syndrome in which three or more of the following criteria are present: unintentional weight loss, weakness, self-reported exhaustion, slow walking speed, and low physical activity. The condition is considered to confer a high risk of falls, disability, hospitalization, and mortality $(13,14)$.

Elderly individuals who required new long-term care insurance (LTCI) certification were found to have inferior survival compared to those who did not $(15,16)$. The current study investigated the factors contributing to new LTCI certification in elderly $\mathrm{HCV}$-positive patients with $\mathrm{CH}$ or compensated LC who underwent DAA therapy.

\section{Patients and Methods}

From September 2014 to May 2016, 123 HCV-positive patients with $\mathrm{CH}$ or compensated LC were treated with DAAs at Koga General Hospital and Kushima Municipal Hospital in Japan. In this 
Table I. Baseline characteristics.

\begin{tabular}{|c|c|c|c|c|c|}
\hline Characteristics & Total $(n=53)$ & $70-74(\mathrm{n}=18)$ & $75-79(n=20)$ & $80-84(n=11)$ & $\geq 85(n=4)$ \\
\hline Age (years) & $78(71-89)$ & $72(71-75)$ & $78(75-80)$ & $81(80-85)$ & $88(88-89)$ \\
\hline Gender (male/female) & $20 / 33$ & $7 / 15$ & $8 / 12$ & $3 / 8$ & $2 / 2$ \\
\hline $\operatorname{ALT}(\mathrm{U} / \mathrm{l})$ & $38(15-224)$ & $42(15-224)$ & $41(18-161)$ & $38(20-156)$ & $38(29-60)$ \\
\hline Platelets $\left(\times 10^{9} / 1\right)$ & $148(79-506)$ & $154(79-268)$ & $145(79-196)$ & $148(94-506)$ & $148(96-234)$ \\
\hline \multicolumn{6}{|l|}{$\mathrm{J}-\mathrm{CHS}$ index } \\
\hline 0 & $27(50.9 \%)$ & $10(55.6 \%)$ & $11(55.0 \%)$ & $5(45.5 \%)$ & $1(25.0 \%)$ \\
\hline 1 & $8(15.1 \%)$ & $2(11.1 \%)$ & $2(10.0 \%)$ & $2(18.2 \%)$ & $2(50.0 \%)$ \\
\hline 2 & $14(26.4 \%)$ & $6(33.3 \%)$ & $4(20.0 \%)$ & $3(27.3 \%)$ & $1(25.0 \%)$ \\
\hline 3 & $4(7.5 \%)$ & $0(0 \%)$ & $3(15.0 \%)$ & $1(9.1 \%)$ & $0(0 \%)$ \\
\hline \multicolumn{6}{|l|}{ KCL index } \\
\hline $0-3$ & $21(39.6 \%)$ & $7(38.9 \%)$ & $8(40.0 \%)$ & $5(45.5 \%)$ & $1(25.0 \%)$ \\
\hline $4-7$ & $22(41.5 \%)$ & $9(50.0 \%)$ & $10(50.0 \%)$ & $3(27.3 \%)$ & $0(0 \%)$ \\
\hline$\geq 8$ & $10(18.9 \%)$ & $2(11.1 \%)$ & $2(10.0 \%)$ & $3(27.3 \%)$ & $3(75.0 \%)$ \\
\hline \multicolumn{6}{|l|}{ MMSE } \\
\hline $28-30$ & $31(58.5 \%)$ & $11(61.1 \%)$ & $12(60.0 \%)$ & $5(45.5 \%)$ & $3(75.0 \%)$ \\
\hline $24-27$ & $14(26.4 \%)$ & $6(33.3 \%)$ & $6(30.0 \%)$ & $1(9.1 \%)$ & $1(25.0 \%)$ \\
\hline$\leq 23$ & $8(15.1 \%)$ & $1(5.6 \%)$ & $2(10.0 \%)$ & $5(45.5 \%)$ & $0(0 \%)$ \\
\hline
\end{tabular}

Data are expressed as n (\%) or median (range). ALT: Alanine aminotransferase; J-CHS index: Japanese Cardiovascular Health Study index; KCL index: Kihon Checklist index; MMSE: mini mental state examination; LTCI: long-term care insurance.

retrospective study, medical record data were collected on 53 of 66 patients who were $\geq 70$ years old, and frailty and cognitive status were investigated before the patients underwent DAA therapy. This study was approved by the Research Ethics Committee of the Faculty of Medicine, University of Miyazaki.

Frailty status was evaluated using two instruments: the JapaneseCardiovascular Health Study index (J-CHS index), which is a modified version of the original CHS frailty index (13), and the Kihon Checklist (KCL) (17-19). The J-CHS index includes five indicators: unintentional weight loss ( $>2 \mathrm{~kg}$ within 6 months), weakness (grip strength $<26 \mathrm{~kg}$ for men or $<18 \mathrm{~kg}$ for women), self-reported exhaustion (feeling tired or fatigued), slow walking speed (usual gait speed $<1.0 \mathrm{~m} / \mathrm{s}$ ), and low physical activity (going outdoors $<1$ time/week). The total score of the index ranges from 0 to 5 , with higher scores indicating a greater likelihood of frailty. Patients with JCHS indexes of 0 were considered non-frail, those with J-CHS indexes of 1 to 2 were considered pre-frail, and those with J-CHS indexes of $\geq 3$ were considered frail. The KCL was developed by the Japanese Ministry of Health, Labour, and Welfare to identify elderly individuals at risk of requiring care or support. The KCL is a self-reporting survey consisting of 25 questions regarding instrumental and social activities of daily living, physical functions, nutritional status, oral function, cognitive function, and depressive mood. Higher KCL scores indicate severely impaired functioning and severe frailty. Patients with KCL scores of $\geq 8$ were considered frail (20). Cognitive functioning was assessed using the Mini Mental State Examination (MMSE). The MMSE investigates the areas of mental functioning: orientation, memory, attention, spatial cognitive, and language functions (21). The total score ranges from 0 to 30 , with low scores indicating impaired cognitive function. Patients with MMSE scores $\leq 23$ were considered to be cognitive impaired, and those with MMSE scores of 24 to 27 were considered to have mild cognitive impairment.

Demographic and clinical parameters were recorded retrospectively, as was the number of individuals who were newly certified for LTCI during the follow-up period.
Statistical analysis. Statistical analysis was performed using SPSS version 20 software (SPSS Inc., Chicago, IL, USA). Baseline continuous data are expressed as medians, and categorical data are expressed as numbers and percentages. The incidence of new LTCI certification was evaluated using logistic regression. $p$-Values $<0.05$ were considered to indicate statistical significance in all analyses.

\section{Results}

Patient characteristics are shown in Table I. The median age was 78.1 years (range $=70.5-88.6$ years), and 20 $(37.8 \%)$ were male. The median alanine aminotransferase level was $38 \mathrm{U} / 1$ (range $=15-224 \mathrm{U} / 1$ ), and the median platelet count was $148 \times 10^{9} / 1 \quad$ (range $\left.=79-506 \times 10^{9}\right)$. Regarding frailty severity, $50.9 \%(\mathrm{n}=27)$ patients were nonfrail, $15.1 \%(n=8)$ were partially frail, and $7.5 \%(n=4)$ were frail. All four frail patients were older than 75 years, and frailty was identified in $15 \%$ of all 75 - to 79 -year-old patients and $10 \%$ of 80 - to 84 -year-old patients. Cognitive impairment was mild in $26.4 \%(n=14)$ patients and severe in $15.1 \%(\mathrm{n}=8)$ patients.

DAA therapy regimens included 24-week daclatasvir plus asunaprevir (DCV+ASV) or 12-week sofosbuvir plus ledipasvir (SOF+LDV) for genotype $1 \mathrm{HCV}$ infection, and 12week sofosbuvir plus ribavirin ( $\mathrm{SOF}+\mathrm{RBV}$ ) for genotype 2 HCV infection. All 53 patients completed the scheduled DAA therapies. Of these patients, 51 achieved SVR, specifically 25 $(92.6 \%)$ of 27 treated with DCV+ASV, 19 (100\%) of 19 treated with SOF+LDV, and seven $(100 \%)$ of seven treated with SOF+RBV. Higher SVR rates were observed in both the non-frail and frail groups, and there was no significant 
Table II. Clinical features of patients who required new LTCI certification after direct-acting antiviral therapy.

\begin{tabular}{|c|c|c|c|c|c|c|c|}
\hline Number & Age (years) & Gender & $\operatorname{ALT}(\mathrm{U} / \mathrm{l})$ & Platelets $\left(10^{9} / 1\right)$ & $\mathrm{J}-\mathrm{CHS}$ index & KCL index & MMSE \\
\hline 1 & 77 & $\mathrm{M}$ & 37 & 139 & 0 & 2 & 30 \\
\hline 2 & 78 & M & 115 & 142 & 0 & 0 & 30 \\
\hline 3 & 88 & $\mathrm{~F}$ & 29 & 105 & 0 & 0 & 29 \\
\hline 4 & 87 & $\mathrm{~F}$ & 60 & 96 & 1 & 14 & 29 \\
\hline 5 & 79 & $\mathrm{~F}$ & 31 & 79 & 2 & 5 & 30 \\
\hline 6 & 81 & M & 37 & 105 & 2 & 16 & 22 \\
\hline 7 & 82 & $\mathrm{~F}$ & 29 & 94 & 2 & 7 & 29 \\
\hline 8 & 88 & M & 38 & 154 & 2 & 15 & 27 \\
\hline 9 & 77 & $\mathrm{~F}$ & 72 & 146 & 3 & 7 & 30 \\
\hline 10 & 79 & M & 30 & 144 & 3 & 1 & 23 \\
\hline
\end{tabular}

Data are expressed as n (\%) or median (range). ALT: Alanine aminotransferase; J-CHS index: Japanese Cardiovascular Health Study index; KCL index: Kihon Checklist index; MMSE: mini mental state examination; LTCI: long-term care insurance.

Table III. Logistic regression analysis to assess the relationship between frailty and new LTCI certification in HCV-positive patients treated with DAAs.

\begin{tabular}{|c|c|c|c|c|}
\hline \multirow[b]{2}{*}{ Variables } & \multicolumn{2}{|c|}{ Univariate model } & \multicolumn{2}{|c|}{ Multivariate model } \\
\hline & Odds ratio $(95 \% \mathrm{CI})$ & $p$-Value & Odds ratio $(95 \% \mathrm{CI})$ & $p$-Value \\
\hline Male & $1.9(0.5-7.5)$ & 0.379 & & \\
\hline Age $(\geq 85)$ & $18.0(1.6-198.5)$ & 0.018 & $34.3(2.4-500.0)$ & 0.010 \\
\hline $\operatorname{ALT}(\geq 100 \mathrm{U} / \mathrm{l})$ & $0.8(0.1-8.2)$ & 0.884 & & \\
\hline Platelets $\left(\leq 100 \times 10^{9} / 1\right)$ & $5.7(1.0-34.2)$ & 0.056 & & \\
\hline $\mathrm{J}$-CHS index ( $\geq 2$ points) & $3.9(0.9-16.2)$ & 0.063 & $6.6(1.2-37.8)$ & 0.034 \\
\hline MMSE ( $\leq 23$ points $)$ & $0.8(1.5-15.9)$ & 0.746 & & \\
\hline KCL index ( $\geq 8$ points) & $4.1(0.9-19.0)$ & 0.070 & & \\
\hline Reduced gait speed slows down & $2.3(0.6-9.4)$ & 0.242 & & \\
\hline Loss of grip strength & $2.2(0.5-10.7)$ & 0.326 & & \\
\hline
\end{tabular}

Data are expressed as n (\%) or median (range). ALT: Alanine aminotransferase; HCV: hepatitis C virus; J-CHS index: Japanese Cardiovascular Health Study index; KCL index: Kihon Checklist index; MMSE: mini mental state examination; LTCI: long-term care insurance.

difference in SVR rate between the two groups (96\% in nonfrail patients and $96 \%$ in frail patients, $p=0.9704$ ).

Fifteen months after the start of DAA therapy, 10 (18.9\%) of the 53 patients had qualified for LTCI certification. At the start of DAA therapy, the median age of these patients was 80.6 years (range $=77.1-88.6$ years), and five $(50.0 \%)$ were males. Further, $70 \%(n=7)$ were pre-frail and $20 \%(n=2)$ were frail. Mild cognitive impairment was mild in $10 \%$ $(n=1)$ and severe in $20 \%(n=2)$ (Table II).

Univariate analysis revealed that only one factor, namely age $\geq 85$ years, was associated with new LTCI certification. Multivariate analysis showed that two factors, namely age $\geq 85$ years [odds ratio $(\mathrm{OR})=34.3,95 \%$ confidence interval $(\mathrm{CI})=2.4-500, p=0.010]$ and $\mathrm{J}-\mathrm{CHS}$ index $\geq 2 \quad(\mathrm{OR}=6.6$, $95 \% \mathrm{CI}=1.2-37.8, p=0.034)$, were independently associated with new LTCI certification (Table III).

\section{Discussion}

DAA therapy for $\mathrm{HCV}$-positive patients with $\mathrm{CH}$ or compensated LC has drastically increased the rate of $\mathrm{HCV}$ eradication (6). In our cohort, $96 \%$ of treated patients achieved SVR. Neither frailty nor cognition status had an effect on SVR rate. By 15 months after the start of DAA therapy, $18.9 \%$ patients required new LTCI certification. Two factors, specifically age $\geq 85$ years and J-CHS index $\geq 2$, were independently associated with new LTCI certification.

Before the DAA era, the main therapeutic option for HCVpositive $\mathrm{CH}$ patients was pegylated alpha-interferon (PegIFN $\alpha$ ). Peg-IFN based therapies resulted in SVR rates of 21 to $56 \%(22,23)$. However, elderly patients receiving these therapies had poor SVR rates, and some patients were unable to continue treatment due to fever, fatigue, or depression 
(24). Since DAAs were more likely to result in SVR and associated with a lower incidence of adverse effects, the indication for anti-HCV therapy expanded to include elderly patients. In fact, the SVR rate in our cohort was $96 \%$ in patients aged $\geq 70$ years.

Nonetheless, $18.9 \%$ of these patients required new LTCI certification by 15 months after the start of DAA therapy. A previous study showed that the prognosis of patients requiring new LTCI certification was inferior to that of patients who did not $(15,16)$. The main aim of antiviral therapy for HCVpositive patients with $\mathrm{CH}$ or compensated $\mathrm{LC}$ is to decrease mortality caused by $\mathrm{HCV}$-associated liver diseases such as LC and HCC, and therefore patients with shorter survival after DAA therapy would receive little benefit from these agents (24). Further, since DAA therapy is expensive in Japan (9), its indication should be considered in view of social insurance (25). We therefore defined new LTCI certification as a surrogate marker of mortality and morbidity, and clarified that this marker was associated with two factors, namely age $\geq 85$ years old and J-CHS index $\geq 2$. Our study was retrospective and was based on clinical practice, with each attending physician deciding on the therapeutic indications in their patients. At the start of DAA therapy, about one-third of patients had a J-CHS index $\geq 2$. They completed the scheduled DAA treatment and achieved high SVR rates, although some subsequently required new LTCI certification. Preventing frailty after DAA therapy in elderly patients might improve their survival, and those with a CHS index $\geq 2$ might need exercise therapy, nutrition therapy, and infection prevention measures to prevent the progression of frailty.

\section{Limitations}

This study was retrospective and observational in nature, and enrolled a small number of patients. A prospective study involving a larger, independent cohort must be performed to validate the current findings.

\section{Conflicts of Interest}

The Authors have no conflicts of interest to declare in relation to this study.

\section{Authors' Contributions}

N.K., K.K., Y.O., and K.S.: Concept, design, statistical analysis and final review; K.K., Y.M., T.M., T.O., M.T., H.I., and S.H.: Data collection; K.N.: Final review and approval.

\section{Acknowledgements}

The Authors thank N. Mihara, A. Harada (Koga General Hospital), T. Nobe, R. Muranaka, M. Suzuki (Kushima Municipal Hospital), and each rehabilitation staff member for their assessments of frailty and the MMSE.

\section{References}

1 Hoofnagle JH: Course and outcome of hepatitis C. Hepatology 36(5 Suppl 1): S21-S29, 2002. PMID: 12407573. DOI: 10.1053/jhep.2002.36227

2 Seeff LB: Natural history of chronic hepatitis C. Hepatology $36(5$ Suppl 1): S35-S46, 2002. PMID: 12407575. DOI: 10.1053/jhep. 2002.36806

3 Sato S, Tanaka K, Nojiri K, Kumamoto T, Mori R, Taniguchi K, Matsuyama R, Takeda K, Ueda M, Akiyama H, Taguri M and Endo I: Hepatic resection for hepatocellular carcinoma in the elderly: Selecting hepatectomy procedures based on patient age. Anticancer Res 35(12): 6855-6860, 2015. PMID: 26637907.

4 Kobayashi M, Suzuki F, Fujiyama S, Kawamura Y, Sezaki H, Hosaka T, Akuta N, Suzuki Y, Saitoh S, Arase Y, Ikeda K and Kumada H: Sustained virologic response by direct antiviral agents reduces the incidence of hepatocellular carcinoma in patients with HCV infection. J Med Virol 89(3): 476-483, 2017. PMID: 27531586. DOI: 10.1002/jmv.24663

5 Kaneko T, Kanda T, Nirei K, Matsumoto N, Yamazaki M, Shibata T, Tamura A, Ogawa M, Nakajima N, Matsuoka S, Kuroda K, Komoriya T, Yamamoto $\mathrm{T}$, Takayama $\mathrm{T}$ and Moriyama M: Follow-up results of $H C V$ GT2 patients after sofosbuvir/ribavirin therapy: Careful attention to occurrence of HCC. Anticancer Res 39(7): 3855-3862, 2019. PMID: 31262913. DOI: 10.21873/anticanres.13535

6 Tanaka J, Koyama T, Mizui M, Uchida S, Katayama K, Matsuo J, Akita T, Nakashima A, Miyakawa Y and Yoshizawa H: Total numbers of undiagnosed carriers of hepatitis $\mathrm{C}$ and $\mathrm{B}$ viruses in Japan estimated by age- and area-specific prevalence on the national scale. Intervirology 54(4): 185-195, 2011. PMID: 21454956. DOI: $10.1159 / 000324525$

7 Karino Y: Innovation in Hepatitis C Treatment. Journal Of The Japanese Association Of Rural Medicine 65(2): 129-135, 2019. DOI: $10.2185 /$ jjrm.65.129

8 Ozono Y, Nagata K, Hasuike S, Iwakiri H, Nakamura K, Tsuchimochi M, Yamada Y, Takaishi Y, Sueta M, Miike T, Tahara Y, Yamamoto S, Shide K, Hidaka T, Kubuki Y, Kusumoto K, Ochiai T, Kato J, Komada N, Hirono S, Kuroki K, Shigehira $\mathrm{M}$ and Shimoda K: Efficacy and safety of sofosbuvir and ledipasvir in Japanese patients aged 75 years or over with hepatitis C genotype 1. World J Hepatol 9(36): 1340-1345, 2017. PMID: 29359017. DOI: 10.4254/wjh.v9.i36.1340

9 Younossi ZM, Tanaka A, Eguchi Y, Henry L, Beckerman R and Mizokami M: Treatment of hepatitis $\mathrm{C}$ virus leads to economic gains related to reduction in cases of hepatocellular carcinoma and decompensated cirrhosis in Japan. J Viral Hepat 25(8): 945951, 2018. PMID: 29478258. DOI: 10.1111/jvh.12886

10 Statistics and Information Department, Minister's Secretariat, Ministry of Health, Labor and Welfare of Japan: Abridged Life Tables for Japan 2016. Tokyo: Health and Welfare Statistics Association. 2016 (in Japanese). Available at: http:// www.mhlw.go.jp/toukei/saikin/hw/life/life16/dl/life16-15.pdf [Last accessed on March 18, 2018]

11 Kaishima T, Akita T, Ohisa M, Sakamune K, Kurisu A, Sugiyama A, Aikata H, Chayama K and Tanaka J: Costeffectiveness analyses of anti-hepatitis $\mathrm{C}$ virus treatments using quality of life scoring among patients with chronic liver disease in Hiroshima prefecture, Japan. Hepatol Res 48(7): 509-520, 2018. PMID: 29316059. DOI: 10.1111/hepr.13053 
12 Ciaccio A, Cortesi PA, Bellelli G, Rota M, Conti S, Okolicsanyi S, Rota M, Cesana G, Mantovani LG, Annoni G and Strazzabosco M: Direct-acting antivirals combination for elderly patients with chronic hepatitis C: A cost-effectiveness analysis Liver Int 37(7): 982-994, 2017. PMID: 27943549. DOI: 10.1111/ liv.13339

13 Fried LP, Tangen CM, Walston J, Newman AB, Hirsch C, Gottdiener J, Seeman T, Tracy R, Kop WJ, Burke G, McBurnie MA and Cardiovascular Health Study Collaborative Research Group: Frailty in older adults: evidence for a phenotype. J Gerontol A Biol Sci Med Sci 56(3): M146-M156, 2001. PMID: 11253156. DOI: 10.1093/gerona/56.3.m146

14 Kuwada K, Kuroda S, Kikuchi S, Yoshida R, Nishizaki M, Kagawa $\mathrm{S}$ and Fujiwara T: Clinical impact of sarcopenia on gastric cancer. Anticancer Res 39(5): 2241-2249, 2019. PMID: 31092415. DOI: 10.21873 /anticanres.13340

15 Ministry of Health, Labor and Welfare of Japan. Guideline of Calculation method of Healthy life expectancy. 2012 (in Japanese). Available at: http://toukei.umin.jp/kenkoujyumyou/ syuyou/kenkoujyumyou_shishin.p df [Last accessed on March 18, 2018]

16 Kamegaya T, Yamaguchi $\mathrm{H}$ and Hayashi K: Evaluation by the Basic Checklist and the risk of 3 years incident long-term care insurance certification. J Gen Fam Med 18(5): 230-236, 2017. PMID: 29264032. DOI: 10.1002/jgf2.52

17 The Research Fund for Longevity Sciences (22-1) from the National Center for Geriatrics and Gerontology (NCGG), Japan in 2014 (in Japanese). Available at: http://www.ncgg.go.jp/ncggkenkyu/documents/25-11.pdf [Last accessed on March 18, 2018]

18 Arai $\mathrm{H}$ and Satake S: English translation of the Kihon Checklist. Geriatr Gerontol Int 15(4): 518-519, 2015. PMID: 25828791. DOI: $10.1111 /$ ggi.12397

19 Sewo Sampaio PY, Sampaio RA, Yamada M and Arai H: Systematic review of the Kihon Checklist: Is it a reliable assessment of frailty? Geriatr Gerontol Int 16(8): 893-902, 2016. PMID: 27444395. DOI: 10.1111/ggi.12833

20 Satake S, Senda K, Hong YJ, Miura H, Endo H, Sakurai T, Kondo I and Toba K: Validity of the Kihon Checklist for assessing frailty status. Geriatr Gerontol Int 16(6): 709-715, 2016. PMID: 26171645. DOI: 10.1111/ggi.12543
21 Folstein MF, Folstein SE and McHugh PR: "Mini-mental state". A practical method for grading the cognitive state of patients for the clinician. J Psychiatr Res 12(3): 189-198, 1975. PMID: 1202204. DOI: 10.1016/0022-3956(75)90026-6

22 Fried MW, Shiffman ML, Reddy KR, Smith C, Marinos G, Gonçales FL Jr, Häussinger D, Diago M, Carosi G, Dhumeaux D, Craxi A, Lin A, Hoffman J and Yu J: Peginterferon alfa-2a plus ribavirin for chronic hepatitis $\mathrm{C}$ virus infection. $\mathrm{N}$ Engl $\mathrm{J}$ Med 347(13): 975-982, 2002. PMID: 12324553. DOI: 10.1056/NEJMoa020047

23 Manns MP, McHutchison JG, Gordon SC, Rustgi VK, Shiffman M, Reindollar R, Goodman ZD, Koury K, Ling M and Albrecht JK: Peginterferon alfa- $2 b$ plus ribavirin compared with interferon alfa- $2 b$ plus ribavirin for initial treatment of chronic hepatitis C: a randomised trial. Lancet 358(9286): 958-965, 2001. PMID: 11583749. DOI: 10.1016/s0140-6736(01)06102-5

24 Sato I, Shimbo T, Kawasaki Y, Mizokami M and Masaki N: Efficacy and safety of interferon treatment in elderly patients with chronic hepatitis C in Japan: A retrospective study using the Japanese Interferon Database. Hepatol Res 45(8): 829-386, 2015. PMID: 25196978. DOI: 10.1111/hepr.12419

25 Ciaccio A, Cortesi PA, Bellelli G, Rota M, Conti S, Okolicsanyi S, Rota M, Cesana G, Mantovani LG, Annoni G and Strazzabosco M: Direct-acting antivirals combination for elderly patients with chronic hepatitis C: A cost-effectiveness analysis. Liver Int 37(7): 982-994, 2017. PMID: 27943549. DOI: 10.1111/liv.13339
Received May 22, 2021

Revised June 28, 2021

Accepted June 29, 2021 